International Journal of Soft Computing 6(4): 91-101, 2011

ISSN: $1816-9503$

(C) Medwell Journals, 2011

\title{
Facilitating Admissions Process Through Intranet Technology at the Imo State University, Owerri
}

\author{
Ukwandu Elochukwu Anthony \\ Imo State University, Owerri, Nigeria
}

\begin{abstract}
Intranet technology is an organizational internal network of computers based on the same technology as World Wide Web using TCP/IP protocol. The motivation to give Imo State University's Admissions process a facelift by providing a system that is fully secured, computerized, accessible and real-time lead to the development of this study. Object oriented analysis and design methodologies coupled with structured system analysis and design methodologies were combined in the analysis, design and coding of this software to give it the robust nature it deserves to serve the unit optimally. The software: A web based application is to capture students' registration records as it relates to admissions process and archives it for further reference in the database. It is also to print a master record of registered students including course major, entry point, admissions mode, projected year of graduation and major discipline admitted. The expected output of the system is a full list of registered students, their details and perhaps matriculation numbers assigned centrally to eliminate fraud and inconsistence.
\end{abstract}

Key words: Admissions, intranet, technology, protocol, fraud, software

\section{INTRODUCTION}

Technological advancements have placed reliance on computers for all kinds of commercial, educational and client applications. All these applications involve the inflow and outflow of information which brings to play manipulation of data through data processing. Data processing entails techniques such as data reading, data transmission, data reporting, data storage and information retrieval. Processed data produces information which requires storage in a manner that is safe, secure and easily accessible.

As a matter of introduction to this study based on the development of intranet technology as a means of facilitation university admission process, several issues relating to the introductory aspects of the concept of the intranet and requisite background leading to this study, its objective as it relates to required input and expected output from the system, statement of the perceived problem leading to the study of the use of the information system tool, its significance: benefits to university admissions and economic value, the scope of study, limitations and contribution of the study to information and communication body of knowledge were taken into account and justice done to them all.

\section{THEORETICAL FRAMEWORK}

Basically, an intranet is a HTML system restricted entirely within an organization. In many cases, an intranet is hosted on a local network with no connection to the internet in any way. If an intranet exists on systems with internet access, the intranet is typically behind a firewall to prevent restricted access from unauthorized users. Because it is an entirely local restricted network, the intranet is typically utilized to share valuable and proprietary company information.

Organizations use intranets for a variety of company functions. An admissions unit could use intranet facilities to share important information on successful applicants with college/faculty officers, university management and related staff.

\section{DEFINITION OF AN INTRANET}

Intranet is a small internal website running within a secured business environment (Jeff, 2009). The researcher further stated that intranet is basically a network of computers in an organization that is used for sharing of data among the employees.

According to Wikipedia, an intranet is a private computer network that uses internet protocol technologies to securely share any part of an Organization's information or operational systems within that organization (Wikipedia, 2009).

An intranet is a private access system for internal company use, applying internet/World Wide Web technologies.

An intranet is essentially a mini in house internet it is an organization's private, secured computer network system that uses the same concepts, technologies and protocols (Standards) as the internet but operates on 
a Local Area Network (LAN), it incorporates a working, interactive custom environment to serve the business/organization model with familiar internet website like navigation and functionality. It is a corporate networked internal website with other features like internal e-mail, newsgroup and chat facilities (Planet Apex, 2007).

\section{HISTORY OF THE INTRANET AND HOW IT WORKS}

The intranet has its roots embedded in the technology of the internet. It is a network that uses the Internet's Transmission Control Protocol and the Internet Protocol (TCP/IP) for its underlying transport. Shortly after the web became popular, companies began to discover that these web protocols were not only useful for the internet with its worldwide reach but also for a company's Local Area Network (LAN). In other words, TCP/IP can be used on a LAN to create a private internet, a localized version of the World Wide Web (WWW) that only computers on the LAN can access. This became known as intranets because they resemble the internet but work within a simple network rather than across the global network (Laoye, 2005).

The practical use of intranets has only really developed since, around 1995 and their application is being improved upon constantly as they are now common place within different organizations even Nigeria. Besides, the ease with which information can be stored and with which people can communicate with one another will continue to drive the building of intranets as these internal webs are forming from an explosion in the use and understanding of the internet technology from which they originated.

Intranets are digital communication networks linking devices such as computers to each other and to network based applications and services, often within a specific geographic location. Much as the global internet has interconnected computer networks, intranets provide local connectivity, services and applications to their users. Intranet is often home or office networks used to interconnect computers.

Intranet systems surpass old notions of networking geographical places by allowing people to be both networked and an integral part of the infrastructure. These peer to peer communications systems provide unprecedented opportunities as well as serious concerns for the future of community organizing, political activities, media production and communication research. Even as evidence accumulates, demonstrating how these technologies encourage civic engagement, their social trajectory is far from determined and the possibility for a more dystopian outcome cannot be dismissed. Intranets can contain a multiple number of servers or can be designed to operate on a single stand alone server (Millikan, 1996).

\section{HOW THE INTRANET WORKS}

Intranet works inexactly the same way as internet web servers sharing the technological DNA of the internet (Laoye, 2005). That is they use the internet standards of Hypertext Markup Language (HTML), Hypertext Transfer Protocol (HTTP) and Transmission Control Protocol/Internet Protocol (TCP/IP). For an intranet to function properly, all computers connected together in the network must speak and understand these languages and protocols.

Driving the intranet in network server that uses software known as browser usually Netscape Navigator, Microsoft Internet Explorer, Mozilla Firefox and Google Chrome. It is the browser's job to contact the server, receive HTML pages and then interpret and display those pages. When browsers are launched, they will visit a certain location may be a departmental Web page or a company wide Web page. This is the default page for accessing the intranet from any computer attached to the internal network. Also by using hyperlinks to specify files or databases, requests for files are sent from anywhere in the network to the browser. The server accesses the file and sends back a copy of what it contains to the computer that asked for it.

It is the very simplicity of TCP/IP that makes intranet so easy to set up. The web browsers can be connected to virtually any information source from Structured Query Language (SQL) database to highly proprietary information systems. As Fuller and Payar (2003) stated, it is because the browser has evolved far beyond its original uses, it may well become the universal interface to all information resources in the future.

Furthermore, intranets often contain private or sensitive information that organizations do not necessarily want to share with the public at large; they are normally protected from external public access by means of a firewall. A firewall is a system (Software, hardware or both) that enforces an access control policy between two networks. Firewalls are simply artificial barrier that stop unwanted people, external to the organization from entering the local network of the intranet. In addition to unwanted users, firewalls can protect intranets from unwanted data and viruses (Fig. 1).

\section{INTRANET TECHNOLOGY CHARACTERISTICS}

Intranet technology is multipurpose, richly networked and integrated text, graphics, sound and video internet technology supports both structured and unstructured 


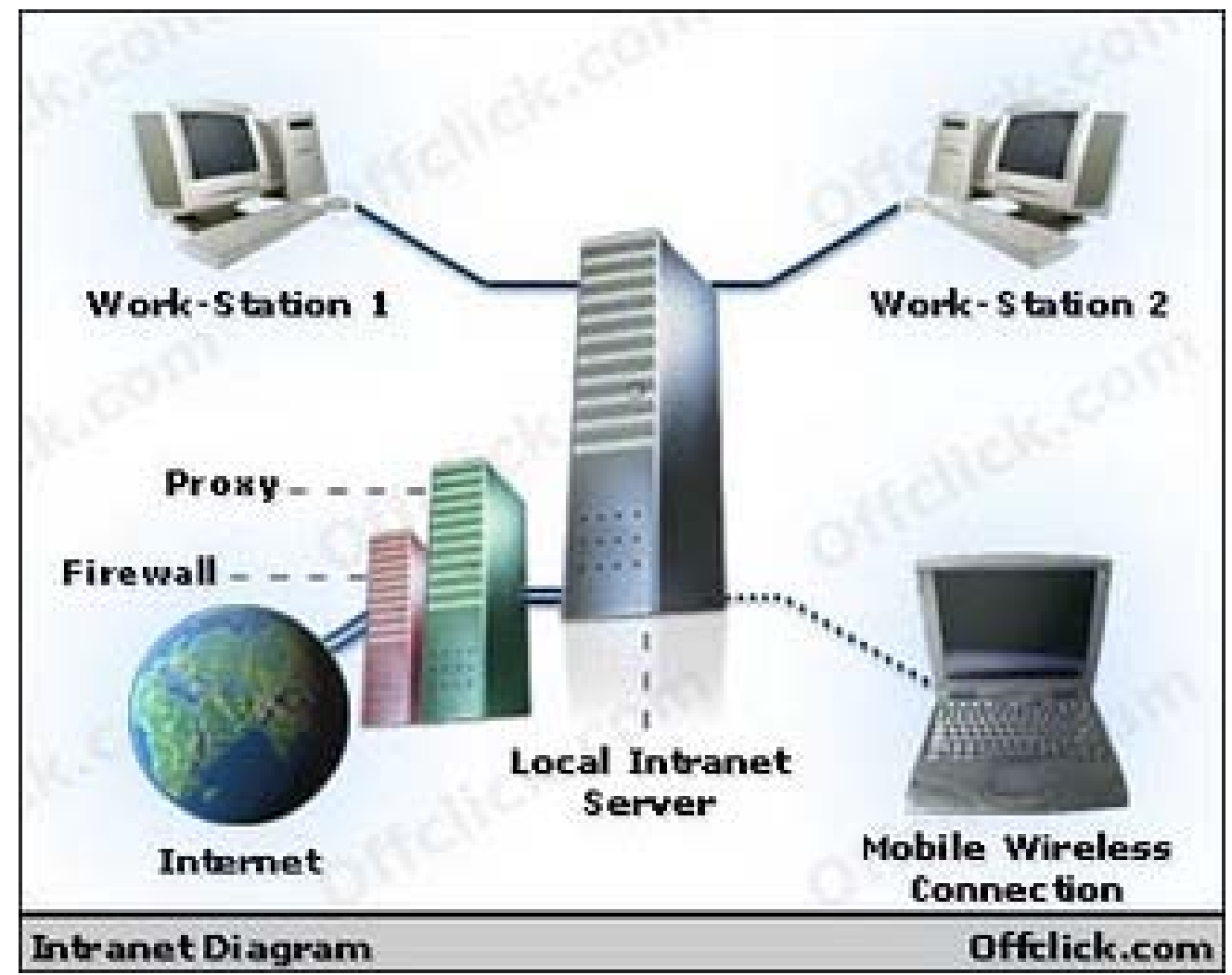

Fig. 1: Diagram of and organizational intranet (Offclick, 2009)

data, mostly by means of Hyper Text Markup Language (HTML) documents as the common langue of the web (Lyytinen and Damsgaard, 2001). Since, HTML describes the presentation of data independent of any specific computing platform, it enables information exchange between diverse computing environments within the organization and across functional boundaries. Such exchanges are facilitated through departmental intranet servers located behind the organizational firewall which organizational members can readily access using a standard web browser.

Unlike most information technology, intranets do not exclude the presence of other information technology systems. Instead, intranet technology is the unifier that can integrate existing information technology systems and provides legacy systems with a new graphical interface. As such intranet technology can unify various computer-based systems in the organization into one rich system with the web browser as the universal interface.

\section{INTRANETS IN EDUCATION}

This is the deployment of intranet facilities in an educational institution like university/college/school. The deployment of intranet-based technology is best suited in an institution with multiple computers in different locations and thousands of students could have the information needs that may benefit significantly from implementing its own intranet. Educational intranet when properly implemented, truly offer the advantage of facilitating innovative ways of supporting students through exciting and interactive computer-based learning, information sourcing and training.

\section{ADVANTAGES OF AN EDUCATIONAL INTRANET}

There are several advantages in creating an educational intranet:

Ease of use: With intranet clients (Browsers), a single front-end can be used to access all internal and external resources; users don't need to learn multiple software packages.

Cost effectiveness: Intranet tools are inexpensive in initial purchase and deployment. A variety of client and serverside software is almost free for academic or noncommercial use. The intranet's platform independence usually eliminates the need to create different versions of the same application. Setting up an intranet can also save 
resources. For example, office and phone directories can be made available in an electronic form on the intranet, instead of printing them.

Asynchronous global information: Information can be accessed anytime and anywhere thus, overcoming the time and space dependent limitations.

Universal communication: Intranets provide a more efficient communication link as it suggests a better note of communication over typical oral and written form of communication. With paper authorization, an individual on an intranet can interact with any other individual within the internal network.

Publishing: Through multimedia support, the WWW technology offers a complete environment for publishing information in dynamic form. Hypermedia makes this information reusable in instant referencing.

Security: Protecting information even within an educational network is critical. Intranets are protected by a firewall, a network configuration usually created by hardware and software that forms a boundary between networked computers within the firewall from those outside the firewall.

Learning: The intranet technology offers several approaches to facilitating and providing the necessary personalized help resources that can be made available to students. By deploying intranets in universities, different kinds of resources and information (Lecture notes, exercises, quizzes, syllabi, etc.) can be made available to enrich the students' academic life.

Two successful examples of intranet implemented in an educational institution in the world: University of Teesside, United Kingdom, under the guidance and inspiration of Philip Barker, a long-time advocate for the integration of ITC (Information Technology Communications) into education, built and developed the use of intranets. Within the university, intranet facilities are available in all staff offices, lecture theatres, laboratories, libraries and other buildings (Laoye, 2005). At the University of Saskatchewan, Canada, the intelligent Intranet HelpDesk is being currently employed to support peer-help among students in the CMPT 100introductory computer science course for non-majors. The intelligent Intranet Peer Help Desk provides an integration and application of previously developed ARIES Laboratory tools within the university for peer help to university teaching. One of its components, CPR, provides a subject-oriented discussion forum and frequently asked questio-list providing students with electronic help. Another component, PHelps suggests an appropriate peer to provide human help. In both cases, it is peer help since, the help originates from students themselves (Laoye, 2005).

\section{THE CHALLENGES OF INTRANETS}

There are few major challenges why intranets are not fully utilized; they may be seen as follows:

Define the intranet purpose: Very often, the root cause of intranets not meeting the needs of the organization, it serves can be identified as a lack of clear unambiguous intranet purpose. It is important to have a vision for the ontranet but the first step in the planning stages is the intranet purpose statement.

The purpose statement should answer the many creators of centre will have about the relevance, importance and target for their study. It also provides the baseline for content management roles, responsibilities and decisions. The intranet purpose should be captured and reflect expected benefits from the investment and include (But not limited to) such items as:

- Improved internal communications

- Costs reduced now and avoided later

- Improved productivity

- Shortened project delivery times

- Increased departmental collaboration

Define content management terms: Organizing intranet teams can pose challenges for organizations but we believe that businesses can distinguish themselves from other similar organizations by the way they organize their information and communication management. Intranet deployment requires an organization to assemble key positions although, the rites can vary, roles and accountability fall into four fundamental activities. These roles can be classified and established as outlined and in view these roles are pre-requisite to effective intranet content management. The roles can be identified as:

- Author/Writer

- Editor

- Page creator

- Publisher

The roles above are also supported by the team that provides strategy and direction to the intranet and is usually cross departmental team that has some organizational grunt.

\section{CONCLUSION}

Intranets, internal networks based on the same technology and protocol as the World Windows Web 
have emerged in the past few years as a very popular medium for communication and information exchange within organisations. Organisations are flocking to this new tool in order to preserve, maintain or improve their market share. Although, the mission of Imo State University admissions unit is not focused on profit, it does seek to enhance communication and productivity. The purpose of this study is to give the Imo State University, Owerri Admissions Unit some guidance that help facilitate its process due to its strategic position in enhancing the image of the university through its service to the external community. A qualitative approach was used in obtaining the data for this study the primary assumption of this research is that the introduction of an intranet is similar to the introduction of any information system and therefore, concludes that the implementers must be savvy by incorporating solution that intranets offer into the vision, mission and strategy of the unit also implementers must masterfully manage change in the unit to smoothly transition into a unit compatible with the new technology. It follows that this thinking provides a backdrop for a unit that understands the technology and can successfully evolve with it. The purpose of this study is to promote the use of intranet technology in the annual handling of admissions process in Imo State University, Owerri between the Admissions unit, Faculty offices and Bursary staffers. It is believed that with the implementation of the technology, the business of admissions processes will be greatly enhanced, time conserved and the University's image is highly improved.
This assumption is based on the fact that with the close of information gap, interaction, ease of access of admissions information by relevant staffers, the admissions processes will be greatly facilitated in Imo State University, Owerri.

\section{RECOMMENDATIONS}

I hereby recommend that the end users of this technology:

- Establish the information system vision and strategy as an integral part of the units vision and strategy

- Align the information system strategy with the organizational mission ensuring information system is understood as an enabler for the units business

- Employ information system personnel who have skills in organisational analysis, management and business who will in turn transfer the skills to the already existing staffers at the unit or to be posted to the unit

- Make sure there is availability of stable power supply supported by automatic voltage regulators and uninterruptible power system

- Ensure the systems are properly shut down at the close of work and all electrical switches turned off

- Ensure a dust-free tiled and air conditioned environment

\section{APPENDIXES}

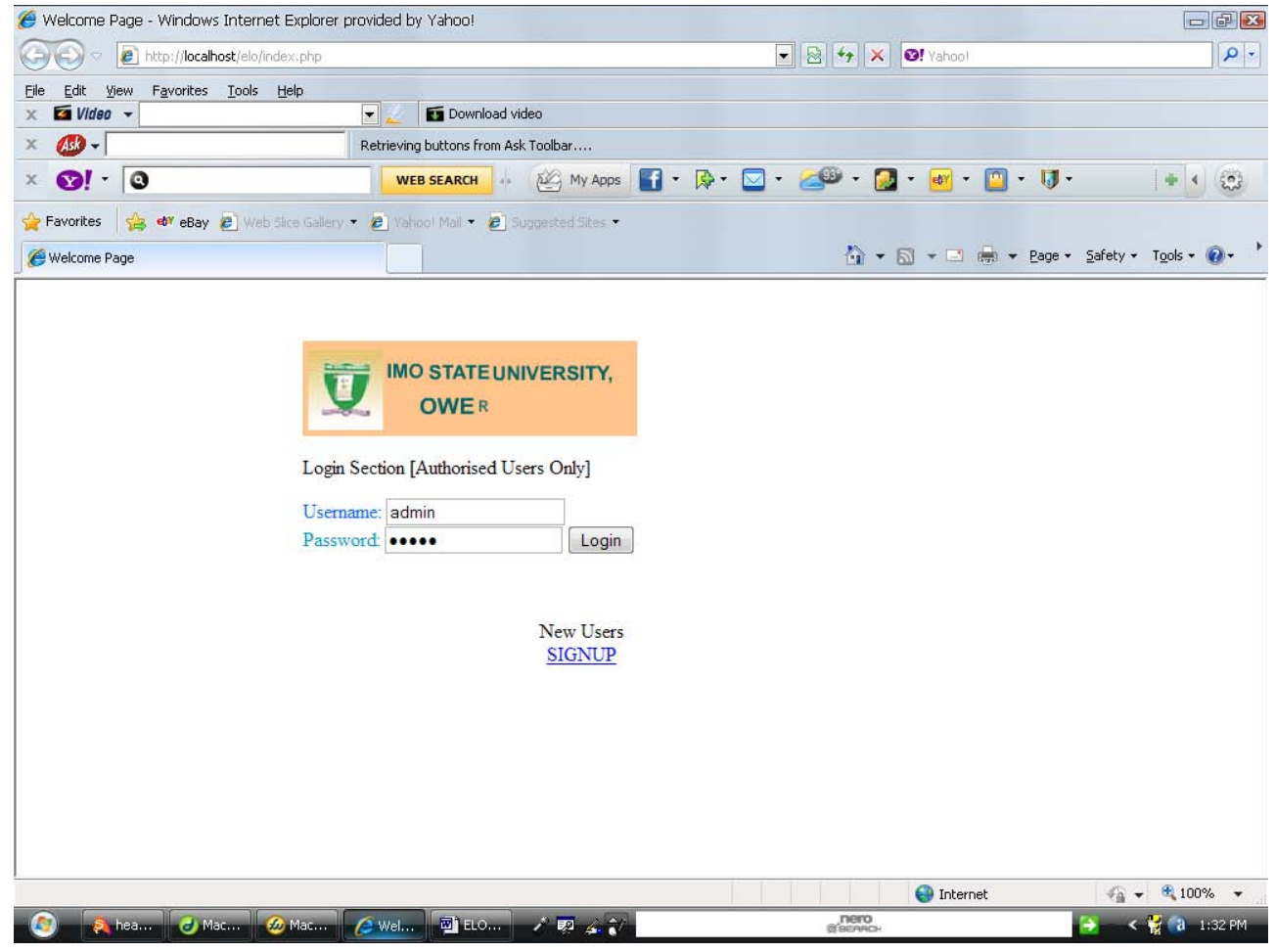


Int. J. Soft Comput., 6 (4): 91-101, 2011

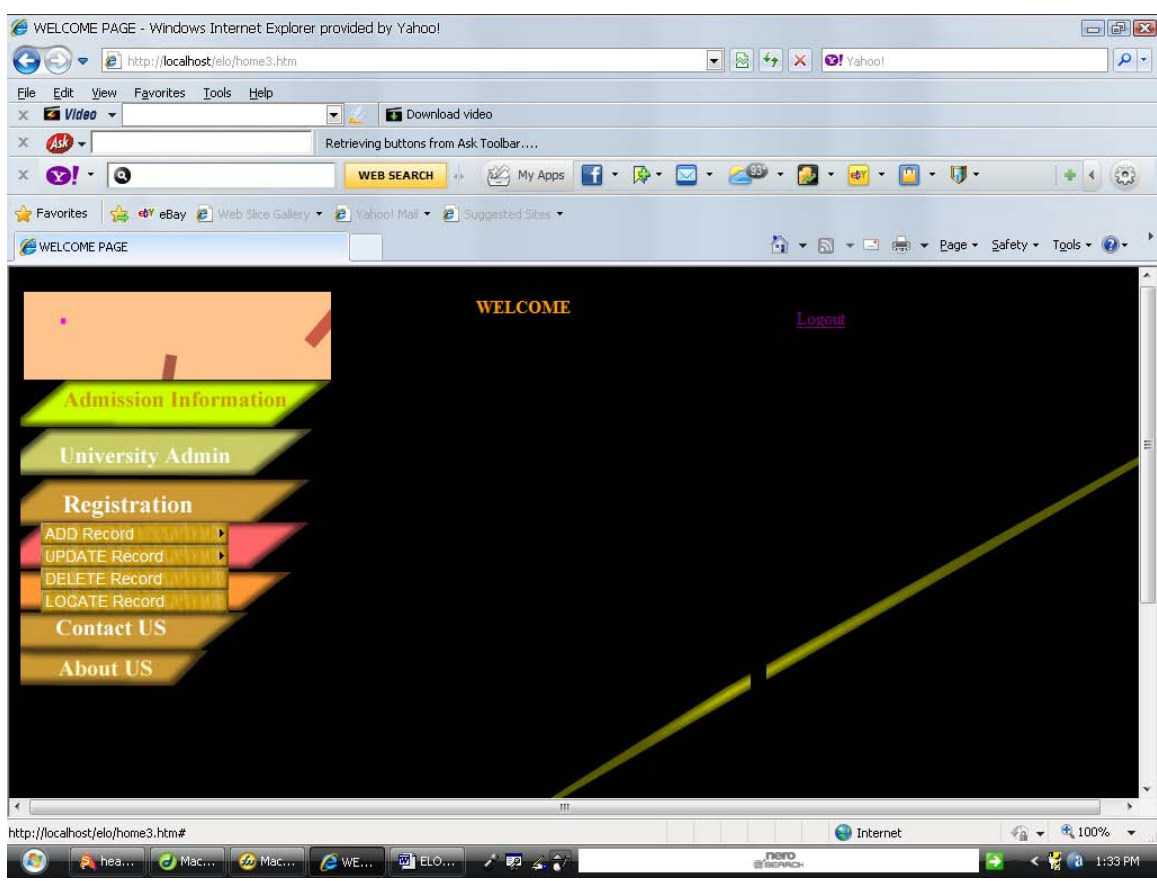

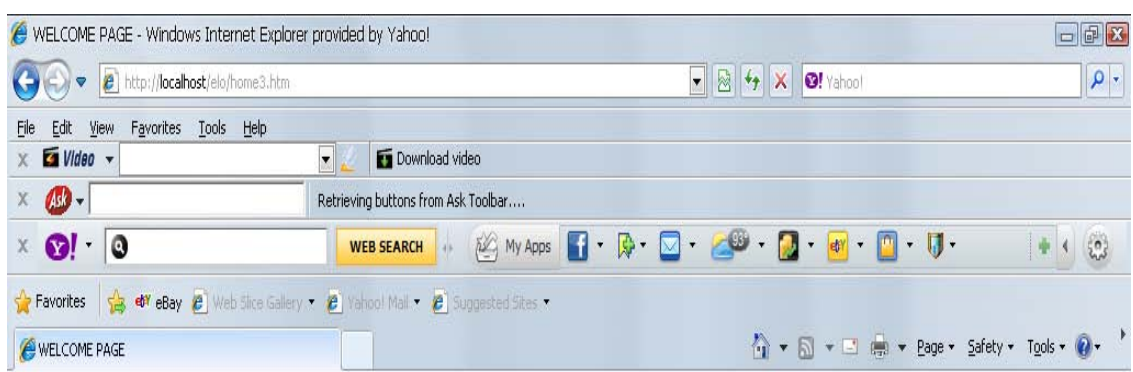

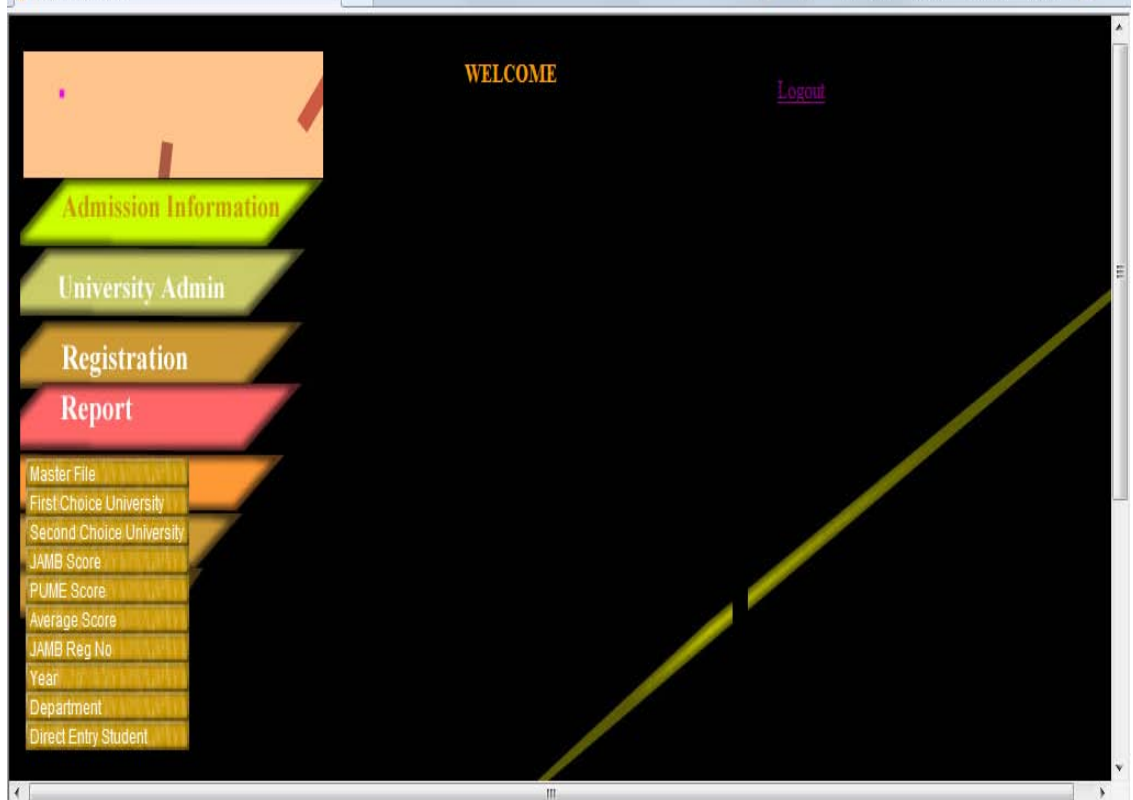

\begin{tabular}{|c|c|c|}
\hline 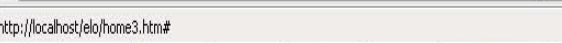 & (9) Intenet & A. $100 \%$. \\
\hline 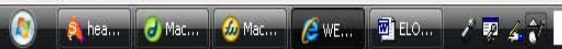 & 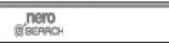 & \\
\hline
\end{tabular}


Int. J. Soft Comput., 6 (4): 91-101, 2011
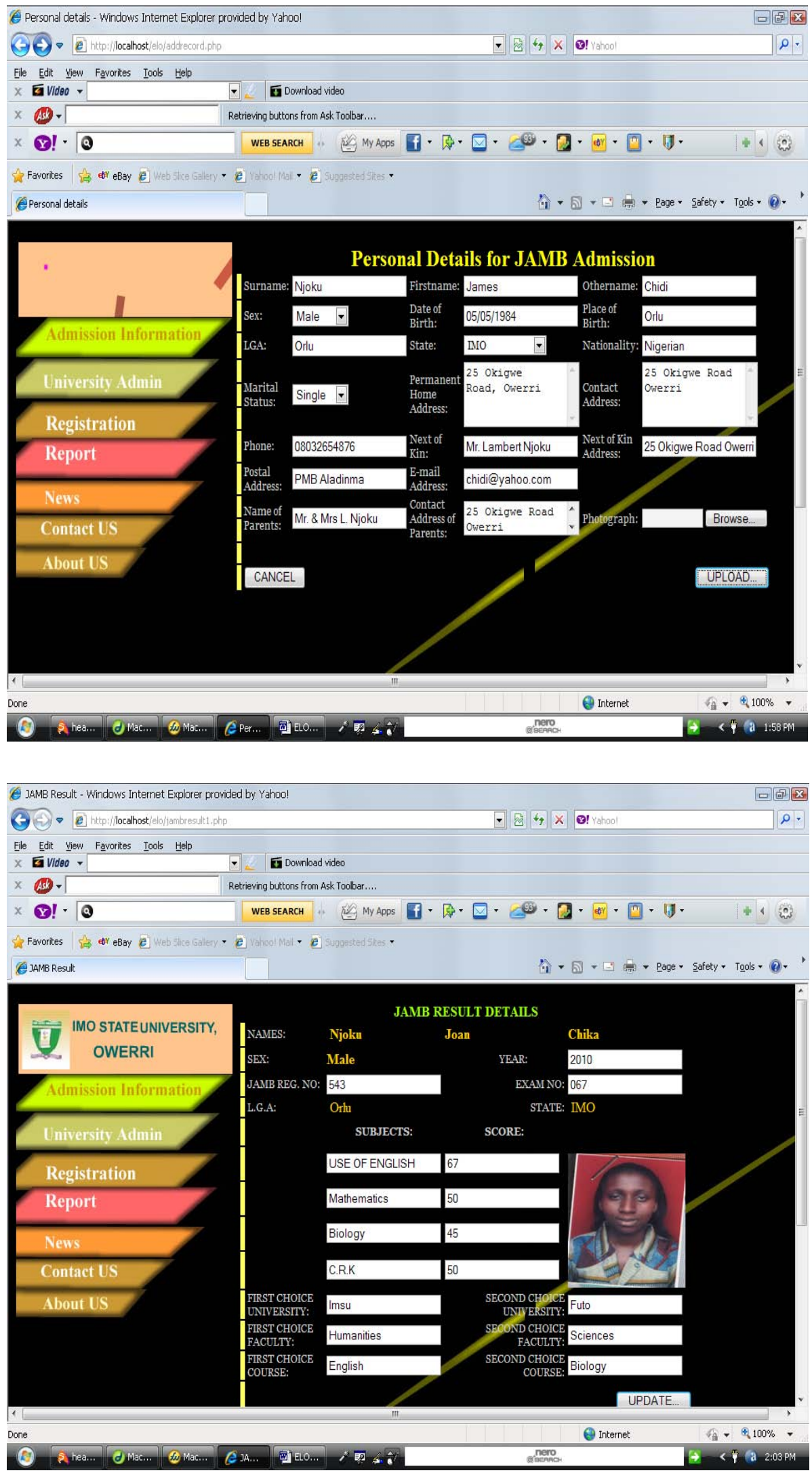
Int. J. Soft Comput., 6 (4): 91-101, 2011
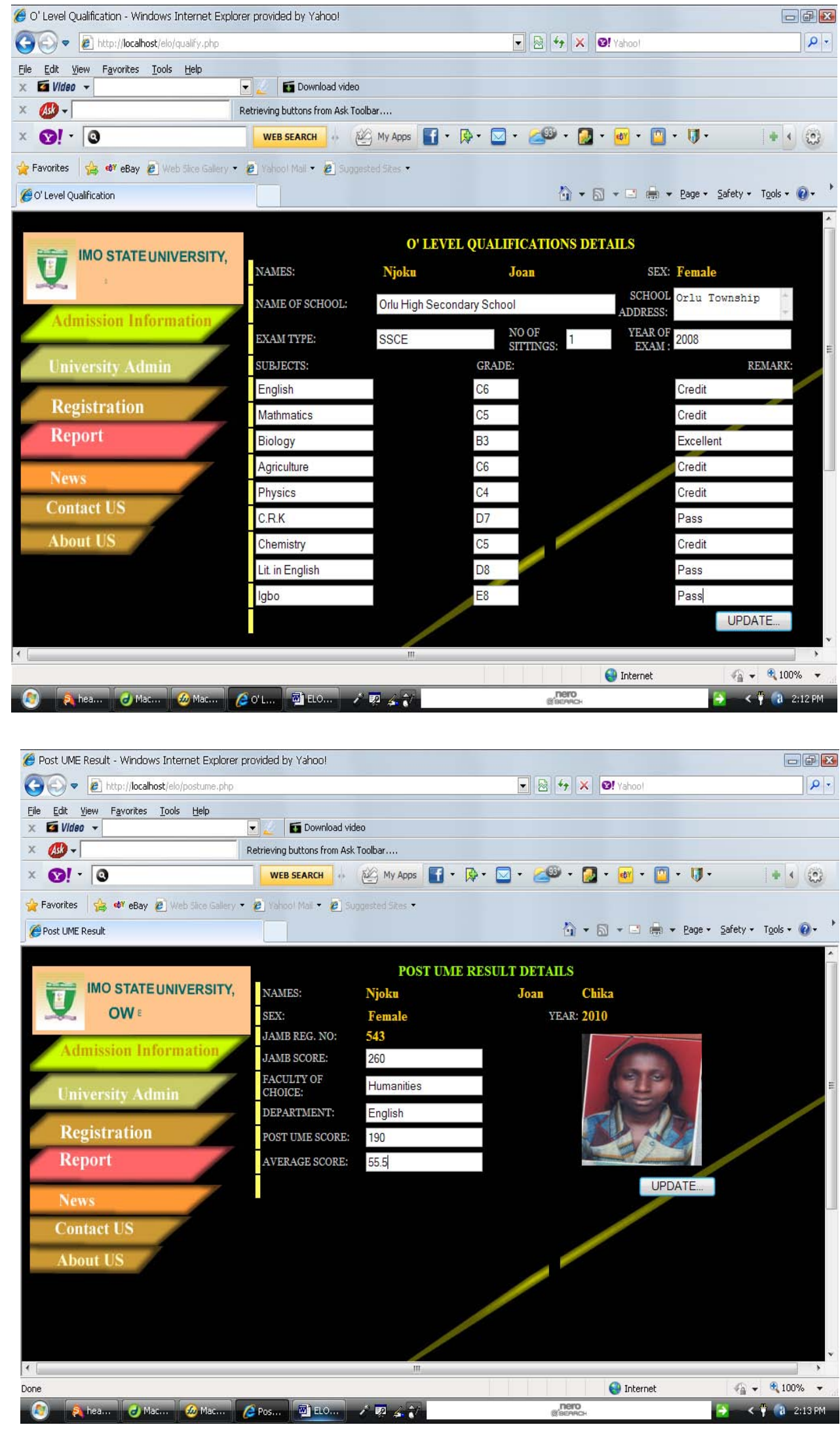
Int. J. Soft Comput., 6 (4): 91-101, 2011
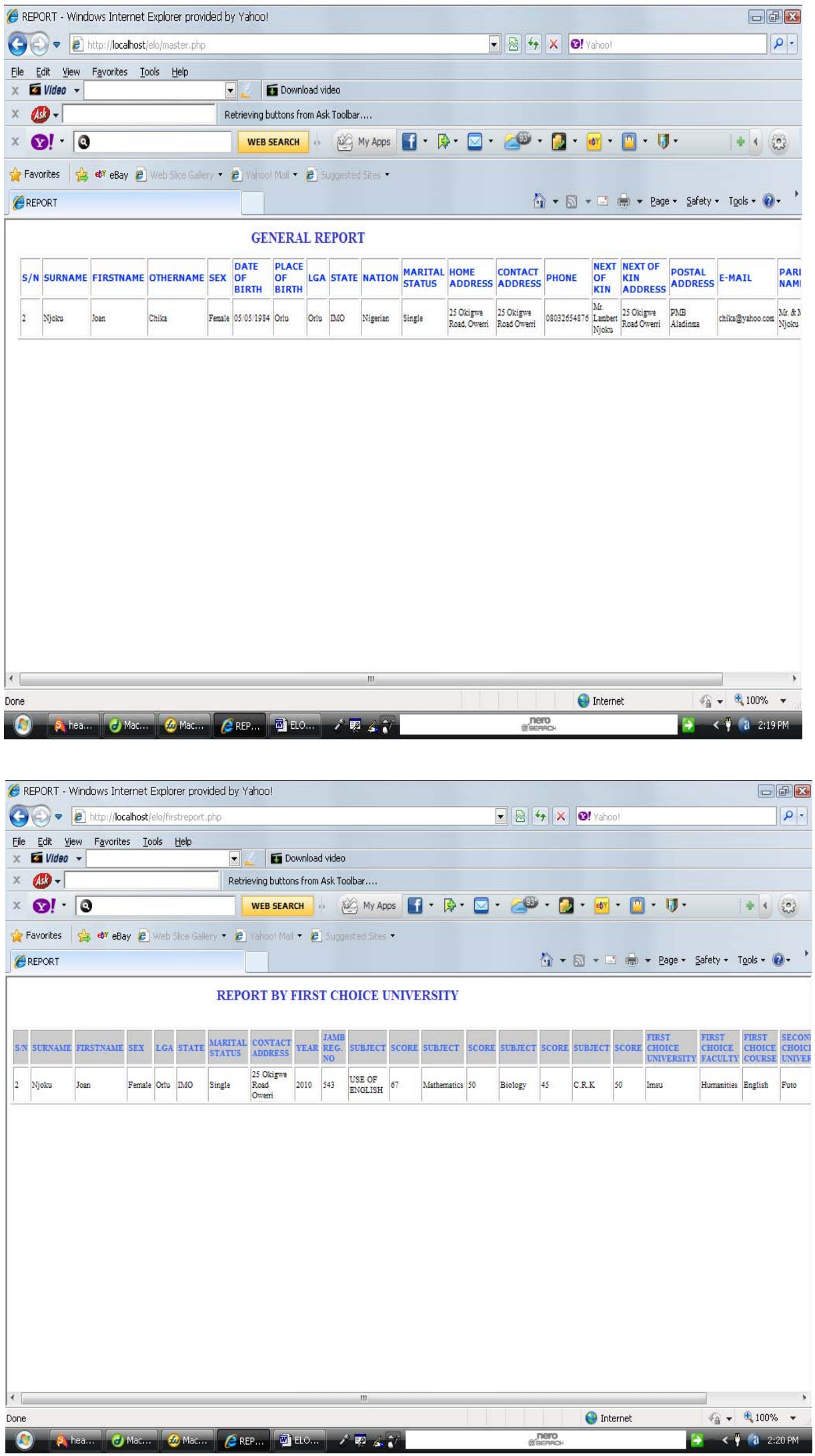
Int. J. Soft Comput., 6 (4): 91-101, 2011
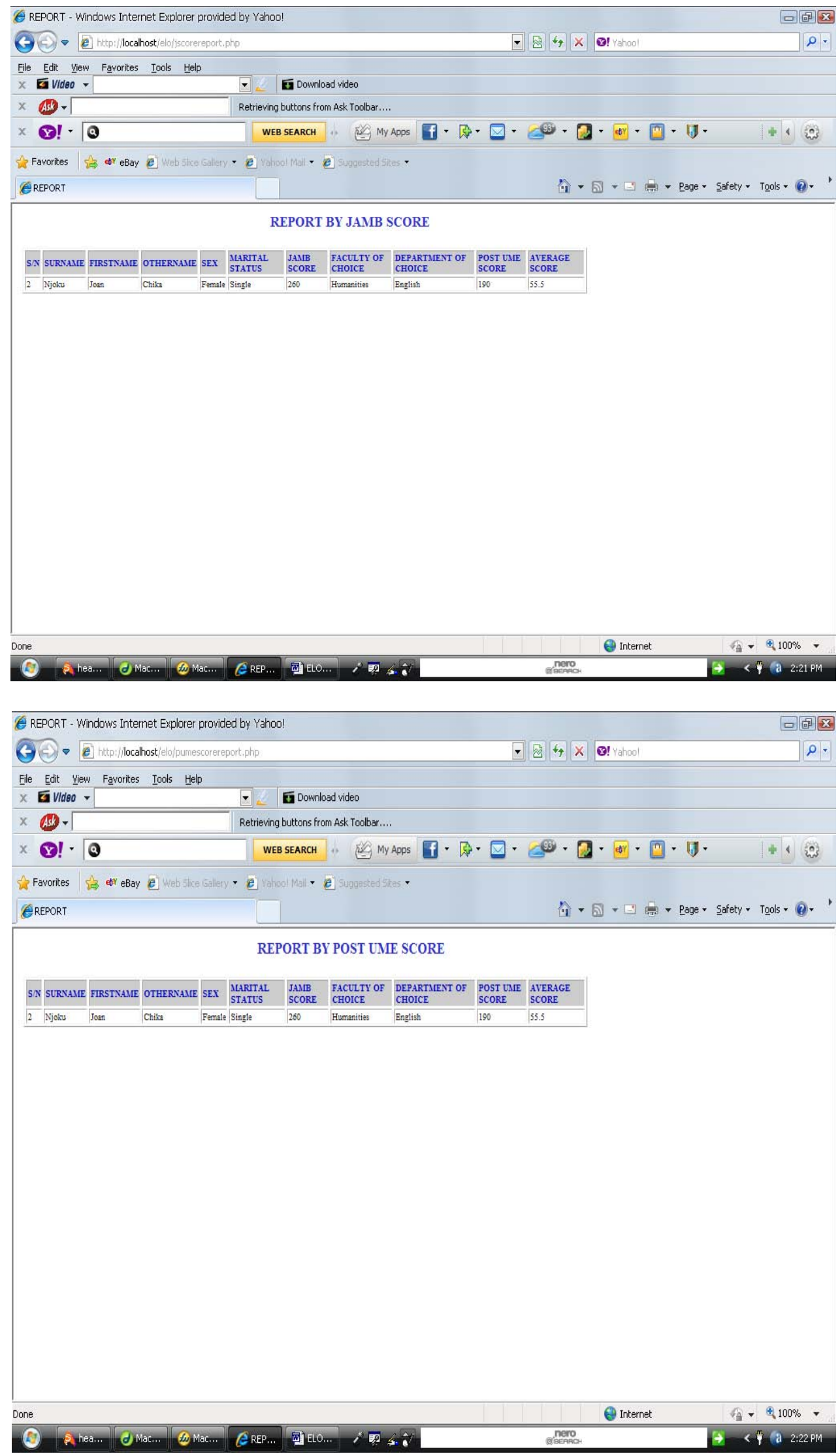


\section{REFERENCES}

Fuller, E. and C. Payar, 2003. This is the dawning of the Age of the Intranet, The Record, April, 2003.

Jeff R. Smuta, 2009. Intranet: What is all the Excitement? Communication World, June, 2009.

Laoye, O.O.S., 2005. Computer-mediated communication: Development of an intranet for a university academic department. Am. J. Undergraduate Res., 4: 25-35.

Lyytinen, K. and J. Damsgaard, 2001. What's wrong with the diffusion of innovation theory? The case of a complex and networked technology. Proceedings of the IFIP Working Group 8.6 Conference, April 2001, Banff, Canada, pp: 173-190.
Millikan, M., 1996. Practical advice for implementing corporate intranets. Telecommuni-cations, 30: 34-37. Offclick, 2009. Intranet development-overview. Offclick, Syria. http://www.offclick.com/intranet.htm.

Planet Apex, 2007. Define intranet: What is an intranet? May 1, 2007. http://planetapex.blogspot.com/2007/ 05/define-intranet-what-is-intranet.htm1.

Wikipedia, 2009. Http://www. wikipedia.com/intranetdef. $\mathrm{htm}$. 